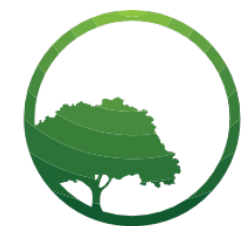

Business \& Social Science IJRBS

\section{Research in Business and Social Science}

IJRBS Vol 6 No 4, ISSN: 2147-4478

Contents available at www.ssbfnet.com/ojs http://dx.doi.org/10.20525/ijrbs.v6i4.747

\title{
Innovation and Performance: The Mediating Effect of Organizational Learning and Technological Capability
}

\section{Neriman Esendemir}

School of Business Administration, Department of Innovation, Entrepreneurship and Management, Yildiz Technical University, Istanbul, Turkey and +90532 4007766

\section{Cemal Zehir}

Prof., School of Business Administration, Department of Innovation, Entrepreneurship and Management, Yildiz Technical University, Istanbul, Turkey and +905357349044

\begin{abstract}
This research aims to investigate the relation of the innovation types such as service innovation, process innovation and management innovation with the performance. Additionally, this study will also focus on whether there is a mediator role of technological capability and organizational learning on performance. The research data were collected from 306 principals and teachers working in medium-large scaled high schools in Istanbul. The research results showed that, as hypothesized, the types of innovations significantly correlated with the performance. Besides, organizational learning and technological capability had partially a mediating effect in the relationship between the innovation types and performance.
\end{abstract}

Key words: Service Innovation, Process Innovation, Management Innovation, Performance, Organizational Learning and Technological Capability.

JEL classification: C51, M15, M31 


\section{Introduction}

Innovation has become an indispensable source of dynamism for today's both national economies and businesses. In this respect, it is possible to summarize the importance of innovation for economy, society and businesses under three headings. Innovation has become a fundamental dynamics of the sustainable economic growth for national and regional economies, and the level of social development and prosperity for societies, as well as the competition power for both businesses and national economies. From this point of view, it can be asserted that innovations in the education sector also constitute a social added value in the social sphere. The main purpose of this study is to investigate how innovations in the education sector reflects on school performance in terms of effectiveness and efficiency from a management perspective.

Educational innovation activities in the public sector rather than private sector are mainly social innovations for social development and improvement due to non-existence of commercial product. Various innovations such as FATIH, EBA, iTEC, ICILS, eTwinning, SENnet, Scientix projects to support education and training with technology have been developed by the Directorate General for Innovation and Education Technologies in Ministry of National Education. These innovations are important developments that accelerate interactive learning and provide a great degree of ease in lectures. However, this situation leads to the fact that innovations related to education are mostly shaped through lectures due to curriculum. When innovation is considered in the sense of creating social value, it is concluded that the innovations made in the education sector should not be limited to only lectures and technology.

Although educational stakeholders in countries desire the development of high-quality teaching skills, they will prefer different practices in practice. However, teaching and learning can be accepted from cultural activities. Transferring useful practices from one culture to another may not be easy (Döbert, Klieme and Sroka, 2004). The reforms can be completely counterproductive. For this reason, while defining the theoretical framework about teaching methods, it is important to select the previously reviewed applications.

As a result, it is necessary to enrich teaching methods for the development of pedagogical innovation and increase the number of professional teaching communities. Non-crowded classes are preferred in the formation of more innovative class environments (Vieluf, Svenja et al. 2012).

The cost of product innovations made through the exchange of textbooks due to curriculum change in every year is very high. A more effective strategy of innovation can be created if the innovations made at this frequency are investigated in strategic terms to create an innovation in the education sector. It is not sufficient for the school performance to focus on a single type of innovation in the education sector. Hence, this study tries to examine what types of innovations have transformed the education sector as a whole.

In the study, firstly the types of innovations were examined and then the effects of product innovation, management innovation and process innovation on school performance were tried to be determined. Thus, it may be possible to see which of the training innovations, that are usually limited to product (service) innovations, are more effective in the sector. However, it has also been investigated whether technological capability in the education sector has an intermediary role on school performance.

Innovative studies in schools and businesses are not enough to develop innovation. There is also a major task for governments in this regard. There is no mechanical prescription to create an innovation system that can bring about a change; it is important that governments provide incentive measures and innovation. (Dutta, Soumitra, Lanvin, Bruno, and Wunsch-Vincent, Sacha, 2016).

\section{Innovation and Performance}

If the innovation will be perceived as renewal, of course, then there will be innovation in the education sector as well. But considering the basic definition of the OECD, it will be more accurate to talk about renewal and reform rather than innovations in education, as the aim is commercialization and marketing of the innovations and inventions. Today western countries consider about innovation in education. However, when we examine our national circumstances, an educational approach called "commercialization and marketing" is not correct. Since innovation has to take care of national characteristics, our understanding in 
this regard must be a reform of education, a reform of the social cause to contribute to our national innovation processes. Even if the word of innovation is used in education, it should definitely be used in this sense (Yamac, 2001).

Scientific and technological developments are deeply affecting the performance of educational organizations as in all organizations. The way to make organizations different and productive in this process should pass through creativity and innovation. Organizations adopting innovative culture and succeeding in establishing this structure has gained significant achievements in harmony with their neighborhood and their development. In this sense, innovation has a vital prescription for the success and continuity of organizations. The progress of developments also compels the educational system and institutions to change (Amabile, 1988).

Another factor affecting the development of innovation is the team atmosphere/climate created by the employees. The four factor theory that determines team climate for innovation states that there are four factors facilitating the formation of innovation; vision, secure participation, task orientation and support. If the vision can be understood, innovation will increase, enrich, be evaluated and accepted by team members. Team members present new ideas and solution proposals without criticism. They will always be informative and offer different solutions, and at the same time will be more carefully negotiative, and as a result of these developments, team members will find support. This theory, which explains the relation between innovation and creativity, has found a wide range of applications in team innovation researches and has been supported in today's analysis studies. (Anderson, Neil, Potočnik, Kristina and Zhou, Jing, 2014).

In educational organizations, innovation comes into play when all the internal and external factors come together. A new product, service, technology, managerial process or structure that interests the school and its employees; a new plan or program to be used in the teaching system; a need for a creative idea and implementation are the internal factors creating innovation. If any change or development has to take place as a result of the needs outside of organization, these are external factors of innovation. Some of the external factors that force schools to change consist of the emergence of private sector educational attitudes, the necessity of basic high schools to attend a university, the perception towards students and parents as customers in educational organizations; the change of information, the easy ways of accessing information, and the rapid development of education technologies. All these reasons have made it necessary for educational organizations to innovate (Ozan and Karabatak, 2013).

The ability of organizations to sustain their assets and perform at a high level depends primarily on their ability to perceive environmental changes and develop innovations that are appropriate for those environmental changes as a whole. With the fact that change and development are an uninterrupted process, innovation and development in the process of internalizing the changes and innovations in the process of internalization seem to have vital importance for the educational institutions in terms of innovation. For this reason, it can be said that school performance and innovation should be considered together so that they can sustain and develop their existence.

There is no mechanical prescription to create a sound innovation system which can make a tremendous impression; it is important that governments provide incentive measures and open space for innovation. (Dutta, Soumitra, Lanvin, Bruno, and Wunsch-Vincent, Sacha, 2016).

Hypothesis 1: Innovation types has a significant effect on the performance.

Hypothesis 1a: Service innovation has a significant effect on school performance.

Hypothesis 1b: Management innovation has a significant effect on school performance.

Hypothesis 1c: Managerial innovation has a significant effect on school performance.

Hypothesis 1d: Internal process innovation has a significant effect on school performance.

Hypothesis 1e: External process innovation has a significant effect on school performance.

Hypothesis 1f: Service innovation has a significant effect on employee performance.

Hypothesis 1g: Internal management innovation has a significant effect on employee performance.

Hypothesis $1 \mathrm{~h}$ : Managerial innovation has a significant effect on employee performance. 
Hypothesis 1i: Internal process innovation has a significant effect on employee performance. Hypothesis 1j: External process innovation has a significant effect on employee performance.

\section{Organizational Learning and Performance}

The concept of organizational learning is described in three ways in the literature. The first is the process of adapting to the changes in the internal and external circles by finding and correcting mistakes of members of the organization. The second is the process of changing organizational behavior or improving current behavior through the organization's timely, accurate and consistent access of information and better thinking. The last is the process of developing organizational performance and adapting to this development by ensuring that employees use their personal skills better by building, completing and organizing information and routines within their organizations' activities and cultures (Kocoglu, Imamoglu, Ince, 2011: 74, Garvin, 1993: 80, Dodgson, 1993: 377).

When the literature on organizational learning and innovation relation is examined, it is seen that there is a meaningful relation between organizational learning and innovation (Vakola, Rezgui, 2000: 177). When this relationship is examined, it can be said that organizational learning is a critical component of the innovation process because it provides a foundation for the formation of new ideas that constitute the foundation of innovation and supports creativity (Meeus, Oerlomans, Hage, 2001: 407). The critical role of organizational learning in the process of innovation creation can be grouped under two headings: "providing support for knowledge management" and "developing creativity." (Avcl, 2009: 127). At the basis of innovations lies new knowledge created by learning at individual, group, organizational and / or industrial level (Luecke, 2008: 37). Innovation capability can therefore be described as a consequence of combinations of existing knowledge in organizations and new knowledge to be created. The level of innovation (incremental, radical and destructive) is related to the high and low level of creation and / or use of new information (Therin, 2002) and the level of innovation reflects the area of implicit and new knowledge found in that innovation. The role of organizational learning, the development of new knowledge and ideas, and the ability to develop creativity, the ability to implement these knowledge and ideas, are the basis for new innovations. Creativity, which can be defined as the ability to make unknown or unexpected combinations among current thinkers, or to bring ideas together in their original form, is a driving force for innovation. Therefore, it can be said that the learning abilities of the organizations have an important influence and role on the formation of innovation. As a result of these determinations, it was pointed out that the individual learner is observed as the changes that take place in the behaviors, and that the organizational learner can be observed by creating innovation.

The learning process, which consists of the two components namely the knowledge base and the intensive effort expenditure, which are in a very close relationship, provides an environment for the construction of the technological capability. (Cohen, Levinthal, 1990). Knowledge base supports strengthening of intensive effort throughout the technology learning process in a spiral structure. Thus, education, skills and qualifications enable people to decode codes and to understand knowledge, and the findings obtained at the end of the information process also make it possible for the student to perform many tasks. (Nelson, Phelps, 1996).

The age we live is the age of speed, transformation and change. This wave of change is changing our life in a planned or unplanned way. For this reason, society is driven by global competition, a talented and creative expert. The factor that is currently transforming the economic, social and industrial aspects of a country is entrepreneurial activity. As a result, a society is driven by another society that is more competitive, which collects creative and dynamic resources, and has financial means and entrepreneurship that will lead to creative business areas. (Fadaee, Akbar and Abd Alzahrh, Haitham Obaid, 2014). From this point of view, studies should be carried out to develop creativity and entrepreneurship skills in educational institutions. Students who do not only use memorizing knowledge, but who can also produce meaning in knowledge, develop different methods in solving a problem and produce unique works should be trained. 
Despite the present world and the future world, the integration and direction of knowledge will gain more importance than learning content. While young people are less focused on producing meaning from the knowledge, they will focus more on what they know. After this tremendous change, scientists, educators and policy makers will suggest that today's children are equipped with different abilities to prepare them for tomorrow's challenges. The new expectations of community structure will lead to the cultivation of a wide range of abilities. A wide range of abilities represent a range of abilities with significant abilities, including abilities of verbal, numerical, and content knowledge in the academic context as well as verbal information, flexibility and problem solving abilities that the training system focuses on. (Winthrop, Rebecca et al. 2016).

Hypothesis 2: Organizational learning has a significant effect on performance.

\section{Technological Capability and Performance}

Technological capacities (TCs) are known as an effective use of technological knowledge in production, engineering and innovation to develop new technologies and products and to create processes that can respond to the needs of the changing economic environment. Technological learning is a process that builds capacity and accumulates technology. For this reason, technological information is not shared equally among firms and cannot be imitated. Technology transfer needs to be learned because technologies cannot talk, express themselves, and the underlying principles of technologies cannot always be understood clearly. For this reason, new technologies require to have new talents, and to invest in technology companies. All of these movements affect businesses and institutions in other sectors, and technologically affected businesses also contribute to this cycle by increasing their technological capabilities (Lall, 1992).

Especially after 2000's, the change in environmental factors, the rapid development of technology and the advances in information technology have laid a foundation for the birth of more systematic and learning national network systems. Innovation systems that are based on mutual exchange of knowledge and technology based on mutual sharing of information and technology and also on interaction and cooperation with other national innovation systems in which enterprises or countries perform innovative activities have begun to be developed instead of closed systems (Uzkurt, 2010)

Hypothesis 3: Technological capability has a significant effect on performance.

\section{Innovation, Organizational Learning, Technological Capability and Performance}

In this study, an identification based on the learning-innovation-performance relation, in which organizational employees play an essential role for organizational learning, will be made by integrating the above three perspectives. According to this approach, organizational learning can be defined as the ability to direct the changes in the internal and external environment on behalf of the organization as a whole, or to provide the necessary differentiations in order to adapt to these changes. The organizational learning process workers emphasized in identification will redirect the organizational understanding in their perceptions by correcting the errors in organizational theories and actions to restructure activities and to simulate the outcomes with anticipation.

Hypothesis 4: Organizational learning and technological capability have an intermediary role in the influence of innovation types on performance.

Hypothesis-4a: Organizational learning and technological capability have an intermediary role in the influence of innovation types on school performance.

Hypothesis-4b: Organizational learning and technological capability have an intermediary role in the influence of innovation types on employee performance. 


\section{Reseach and Methodology}

\section{Sample}

The universe of this research is teachers and administrators working in high schools. The sample of the research is the participants selected randomly from different high schools in Istanbul to represent the universe. The research data were collected using survey method from 306 employees working in these high schools. Among the participants, $194(63.4 \%)$ were female and $112(36.6 \%)$ were male; 67 people $(21,9 \%)$ were between $21-30$ years old, 94 people $(30,7 \%)$ were between $31-40$ years old, 113 people $(36,9 \%)$ were between $41-50$ years old and 32 people $(10,5 \%)$ were 51 years and over. When the working/employee periods of the participants were examined, it was found that the participants has worked as follows: 32 persons $(10.4 \%)$ were between $0-3$ years, 28 persons $(9.1 \%)$ were between $4-6$ years, 30 persons (9.8\%) were between $7-9$ years, 45 persons (14,7\%) between $10-12$ years and 171 persons (56\%) 13 and over years. When the educational status of participants was examined, it was determined that 7 of them $(2.3 \%)$ were college graduates, $214(69.6 \%)$ were university graduates, $82(26.8 \%)$ were graduates and $3(1.0 \%)$ were doctoral graduates.

This study can also be done comparatively in all secondary education institutions of Turkey or international secondary education institutions. Thus, more detailed results can be obtained about the innovation works carried out between inter-country schools.

In our study, we investigated the mediation effect of organizational learning and technological capability in relation to innovation-performance. The same study can also be examined by taking into consideration organization structure, organizational climate, managerial leadership (school director), project expertise (teacher's), teaching methods, or pedagogical innovation parameters in relation to innovation-performance.

\section{Scales}

The scale of innovation types and the scale for management innovation has developed by Celuch et al. (2002), while the scale for product and process innovations developed by Andersen \& Kheam (1998). The scale developed by Andersen \& Kheam (1998) includes three dimensions: process, management, and service. The Cronbach alpha reliability value of the scale was found to be 0.890 (high confidence) in the study. The scale for organizational learning was developed by Chen,(2005). In the study, the Cronbach alpha reliability score of the scale was found to be 0.946 (high reliability). The scale for technological capability was developed by Kaleka (2002). The scale includes three dimensions: process, management, and service. The Cronbach alpha reliability score of the scale was found to be 0.89 (highly reliable) in the study. Performance scale was developed by Kaleka (2002). The scale consists of two dimensions; school and employee performance.

\section{Scale Validity}

Confirmatory factor analysis was applied to the scale. In the factor analysis using the "Basic Components" analysis method and the "Varimax" axis rotation technique, it was firstly examined whether the data were suitable for factor analysis. For this purpose, $\mathrm{KMO}$ and Bartlett test were performed and the results of the KMO sample test were found to be 0,786 and Barlett normal distribution test result was significant ( $p$ $<0.05)$. These values indicate that the sample size is adequate and the data show normal distribution. 


\section{Results}

In the study, Pearson correlations were calculated to reveal the relationships between dependent and independent variables.

Table 1: Correlation between dimensions, safety coefficients and descriptive statistics

\begin{tabular}{|l|c|c|c|c|c|c|c|c|c|c|c|}
\hline \multicolumn{1}{|c|}{ DIMENSIONS } & Aver. & $\mathbf{S . S}$ & $\mathbf{1}$ & $\mathbf{2}$ & $\mathbf{3}$ & $\mathbf{4}$ & $\mathbf{5}$ & $\mathbf{6}$ & $\mathbf{7}$ & $\mathbf{8}$ & $\mathbf{9}$ \\
\hline $\begin{array}{l}\text { 1.Organizational } \\
\text { learning }\end{array}$ & 3,6736 &, 69052 & $\mathbf{( 0 , 9 4 6 )}$ & & & & & & & & \\
\hline $\begin{array}{l}\text { 2.Technological } \\
\text { capability }\end{array}$ & 3,4157 &, 82331 &, $670^{* *}$ & $(0,929)$ & & & & & & & \\
\hline $\begin{array}{l}\text { 3.Internal } \\
\text { process } \\
\text { innovation }\end{array}$ & 4,0283 &, 66571 &, $598^{* *}$ &, $520^{* *}$ & $(0,765)$ & & & & & & \\
\hline $\begin{array}{l}\text { 4.Management } \\
\text { innovation }\end{array}$ & 3,1017 &, 76384 &, $521^{* *}$ &, $433^{* *}$ &, $263^{* *}$ & $(0,803)$ & & & & & \\
\hline $\begin{array}{l}\text { 5.Managerial } \\
\text { innovation }\end{array}$ & 3,6246 &, 84573 &, $638^{* *}$ &, $500^{* *}$ &, $576^{* *}$ &, $282^{* *}$ & $(0,877)$ & & & & \\
\hline $\begin{array}{l}\text { 6. Service } \\
\text { innovation }\end{array}$ & 3,7720 &, 70225 &, $674^{* *}$ &, $540^{* *}$ &, $514^{* *}$ &, $371^{* *}$ &, $505^{* *}$ & $(0,556)$ & & & \\
\hline $\begin{array}{l}7 . \text { External } \\
\text { process } \\
\text { innovation }\end{array}$ & 3,3555 &, 89993 &, $534^{* *}$ &, $523^{* *}$ &, $423^{* *}$ &, $356^{* *}$ &, $403^{* *}$ &, $424^{* *}$ & $(0,759)$ & & \\
\hline $\begin{array}{l}\text { 8.Employee } \\
\text { performance }\end{array}$ & 3,7494 &, 69258 &, $599^{* *}$ &, $560^{* *}$ &, $497^{* *}$ &, $312^{* *}$ &, $552^{* *}$ &, $542^{* *}$ &, $439^{* *}$ & $(0,918)$ & \\
\hline $\begin{array}{l}\text { 9.School } \\
\text { performance }\end{array}$ & 3,5712 &, 71580 &, $657^{* *}$ &, $652^{* *}$ &, $426^{* *}$ &, $498^{* *}$ &, $499^{* *}$ &, $585^{* *}$ &, $391^{* *}$ &, $613^{* *}$ & $(0,933)$ \\
\hline
\end{tabular}

When the correlations of employee performance dimension with other dimensions are examined; organizational learning, technological capability, internal process innovation, management innovation, managerial innovation, service innovation, external process innovation, and school performance dimensions were found to be in a significant and positive relationship. When the correlations of school performance dimension with other dimensions are examined; organizational learning, technological capability, internal process innovation, management innovation, managerial innovation, service innovation, external process innovation, and employee performance dimensions were found to be in a meaningful and positive relationship. When the correlations of the other dimensions are examined, it is seen that all the dimensions are positively related to each other.

Linear regression and hierarchical regression analysis were performed to determine the direct relationships between variables, the power of arguments on dependent variables, and possible mediating roles in existing effects. In the regression analysis, the effect of demographic and personality factors on emotional labor was investigated. It was later researched whether the intention to leave work played an intermediary role in the interaction of personality and emotional labor.

Table 2: Regressions between innovation and performance

\begin{tabular}{|l|c|c|}
\hline \multirow{2}{*}{\multicolumn{1}{c|}{ Independent variables }} & School performance & Employee performance \\
\cline { 2 - 3 } & $\mathbf{B}$ & $\mathbf{B}$ \\
\hline (Constant) &, 568 &, 968 \\
\hline Internal process innovation &, 043 &, $161^{*}$ \\
\hline External process innovation &, 045 &, $127^{*}$ \\
\hline Internal management innovation &, $267^{* * *}$ &, 053 \\
\hline Managerial innovation &, $191^{* *}$ &, $254^{* *}$ \\
\hline Service innovation &, $352^{\text {}}$ &, $246^{* * *}$ \\
\hline$\Delta \mathbf{F}$ & 40,903 & 37,503 \\
\hline$\Delta \mathbf{R 2}$ &, 455 &, 402 \\
\hline
\end{tabular}

Peer-reviewed Academic Journal published by SSBFNET with respect to copyright holders. 
It is observed that the internal management innovation, managerial innovation and service innovation significantly predict the school performance and explain $45 \%$ of the total variance. The internal process innovation, external process innovation, managerial innovation, and service innovation significantly predict employee performance, and explain $40 \%$ of the total variance.

As a result, Hypothesis 1a: Service innovation has a significant effect on school performance, Hypothesis 1b: Management innovation has a significant effect on school performance, Hypothesis 1c: Managerial innovation has a significant effect on school performance, Hypothesis 1f: Service innovation has a significant effect on employee performance, Hypothesis $1 \mathrm{~h}$ : Managerial innovation has a significant effect on employee performance. Hypothesis 1i: Internal process innovation has a significant effect on employee performance and Hypothesis 1j: External process innovation has a significant effect on employee performance, were accepted, but Hypothesis 1d: Internal process innovation has a significant effect on school performance, Hypothesis 1e: External process innovation has a significant effect on school performance and Hypothesis 1g: Internal management innovation has a significant effect on employee performance, were rejected.

Table 3: Regressions between organizational learning, technological capability and innovation

\begin{tabular}{|l|c|c|}
\hline \multirow{2}{*}{\multicolumn{1}{c|}{ Independent Variables }} & School performance & Employee performance \\
\cline { 2 - 3 } & $\mathbf{B}$ & $\boldsymbol{\beta}$ \\
\hline (Constant) &, 890 & 1,448 \\
\hline Organizational Learning &, $404^{* * *}$ &, $400^{* * *}$ \\
\hline Technological Capability &, $385^{* \star *}$ &, $295^{* * *}$ \\
\hline$\Delta \mathbf{F}$ & 125,861 & 92,036 \\
\hline$\Delta \mathbf{R 2}$ &, 514 &, 400 \\
\hline
\end{tabular}

${ }^{*} p<0,10 \quad{ }^{* *} p<0,05 \quad{ }^{* * *} p<0,001$

When the results in the table were examined, it was found that school performance was predicted by organizational learning $(\beta=0.404, p<0.001)$ and technological capability $(\beta=0.385, p<0.001)$ and they significantly explained $51.4 \%$ of total variance $(p<0.01)$. Employee performance was significantly predicted by organizational learning $(\beta=0,400, p<0,001)$ and technological capability $(\beta=0,295, p<0,001)$ and they statistically significantly explained $40 \%$ of total variance significantly $(p<0,01)$.

Following these results, Hypothesis-2 (Organizational learning has a significant effect on performance) and Hypothesis-3 (Technological capability has a significant effect on performance) were accepted.

When the following table is examined, the predicting power of internal management and managerial innovation, which significantly predicts the school performance at first stage, has lost when analytical organizational learning and technological capability were included in the model, and the predicting power of service innovation has decreased. The predicting power of organizational learning and technological capability on school performance has continued after inclusion in the model. In this context, it was determined that organizational learning and technological capability played a full intermediary role between school performance and internal process innovation and managerial innovation; but a partial intermediary role between performance and service innovation. 
Table 4: Results of mediated effects of organizational learning and technological capability

\begin{tabular}{|c|c|c|}
\hline Independent variables & School performance & Employee performance \\
\hline Model-1 & B & B \\
\hline (Constant) & 640 & 1,088 \\
\hline Internal process innovation & 043 &, $106^{*}$ \\
\hline External process innovation & ,045 & $119^{*}$ \\
\hline Internal management innovation &, $295^{\star \star \star}$ & ,053 \\
\hline Managerial innovation &, $213^{\star * \star}$ &, $282^{* * *}$ \\
\hline Service innovation &, $378^{\star \star \star}$ &, $307^{\star * \star}$ \\
\hline$\Delta \mathbf{F}$ & 72,334 & 46,749 \\
\hline$\Delta \mathbf{R 2}$ & ,484 &, 416 \\
\hline Independent variables & School performance & Employee performance \\
\hline & B & B \\
\hline (Constant) &, 568 & 1,042 \\
\hline Internal process innovation &, 043 &, 053 \\
\hline External process innovation & 045 & 040 \\
\hline Internal management innovation & ,170 & ,053 \\
\hline Managerial innovation & ,063 &, $214^{\star *}$ \\
\hline Service innovation &, $223^{* * *}$ &, $219^{* *}$ \\
\hline Organizational Learning &, $198^{*}$ &, $137^{* *}$ \\
\hline Technological Capability &, $273^{* * *}$ &, $177^{* *}$ \\
\hline$\Delta \mathbf{F}$ & 57,275 & 35,118 \\
\hline$\Delta \mathbf{R 2}$ &, 552 &, 443 \\
\hline
\end{tabular}

${ }^{*} \mathrm{p}<0,10 \quad{ }^{* *} \mathrm{p}<0,05 \quad{ }^{* * *} \mathrm{p}<0,001$

In terms of employee performance, the predicting power of internal and external innovation, which significantly predicts the performance at first stage, has lost when analytical organizational learning and technological capability were included in the model, and the predicting power of service and managerial innovation has decreased. The predicting power of organizational learning and technological capability on employee performance has continued after inclusion in the model. In this context, it was determined that organizational learning and technological capability played a full intermediary role between employee performance and internal and external process innovation; but a partial intermediary role between managerial and service innovation.

Following these results, Hypothesis-4a: Organizational learning and technological capability have an intermediary role in the influence of innovation types on school performance, and Hypothesis-4b: Organizational learning and technological capability have an intermediary role in the influence of innovation types on employee performance, were partially accepted.

\section{Discussion and Conclusion}

Innovation is not only a competitive tool for profit-making businesses, but also an important source of dynamism for educational institutions in the public sector. Many of the innovations to improve performance on schools do not create social added value, and they cause high unnecessary expenditures such as costs related to constantly changing textbooks every year. This and similar activities negatively affect the school 
performance and prevent the achievement of desired outputs. Therefore, this study deals with the subdimensions of innovation types that will have a positive effect on performance and also examines the effect of organizational learning and technological capability on innovation types-performance relationship. For this purpose, questionnaires were applied to 306 administrators and teachers in Istanbul general high schools and equivalent public schools.

The results of the research reveal the role of schools in sustaining their existence in the globalized world and the role of innovation needed in the education sector to achieve a higher school performance, and in this sense, remind school administrators of the importance of this issue. This road map, in which the results of the research will reveal towards the practitioners, adds a different originality to the study. One of the aims of this present study together with these evaluations is to examine the relationship between school performance and innovation and to analyze the mediatory effect of organizational learning and technological capability in this area through a field research. In this sense, it can be argued that this study, which was done in a more detailed framework, will contribute to education management literature and therefore it is important.

The study also aims to provide some guidance to the school administrators who are primarily responsible for organizational continuity and development in educational institutions, for creating and developing organizational learning and innovation processes that have direct effects on school performance. Based on the analysis results we have obtained, it is necessary to develop basic types of innovation (service, process and management) in order to improve school and employee performance. In order to achieve this development, it is necessary firstly that school administrators have strategic planning skills and strategic planning of education and training activities in schools. However, it is also important to share the vision of the institution between the administration and the teachers.

Innovative educational institutions need to have a leading educational staff that support the structure, in order to carry out a successful innovation process and make the innovation works sustainable in the school environment. School administrators' management understanding in innovation and creativity is very influential in the shaping of schools' innovative structures. Especially school principals must be individuals who are talented in organizational innovation, and able to develop new business models, build high performance teams with all their employees as well as offer a more flexible work environment.

In addition to the fact that school administrators should be an effective team leader, many issues consisting of clarifying definitions of the employee tasks and objectives, developing an effective mechanism to resolve conflicts within schools, having a constant connection with other schools, communication skills, new training models, rewarding systems and measurement and evaluation systems, will affect the innovation process. A rewarding system that encourages teachers and administrators to innovate is important in the development of an innovative organizational culture. Therefore, it will be beneficial in this sense for the school administrators to be able to make more functional and long-term strategic planning, to have a management understanding that supports innovation and to be subjected to an intensive in-service training program on "innovation management" before being appointed as the manager to create teams that can develop innovation cultures.

The right decisions should be made about what innovations should be made in educational institutions. It should be clearly stated what kind of innovations should be given weight, taking into account the technological infrastructure of schools, the level of success in other schools, and their own needs. It is important that this difference is not ignored, as a school in a rural area and an educational institution in the city center do not need the same innovations. However, over-investment in product innovations in schools where administrative and service innovations should be prioritized often leads to resource waste. Renewal of school books every year without any necessity and decoration of manager rooms in an exaggerated style can be shown as the examples of unnecessary innovation activities.

Based on the fact that innovation is based on information and technology, spreading and controlling the use of technology in schools is important for the sustainability of innovation. It is necessary to establish an open system which allows the flow of new ideas into the school environment. The long period of time in the process of preparing the software in the technological product innovations especially such as smart board 
applications in the schools often causes the equipment to go out of date. For this reason, there are various problems in the transfer of technological product innovations to other schools. It is necessary to take relevant precautions and realize a national innovation management, in order to prevent such problems and provide simultaneous technological equipment to the schools.

By assigning up to 5 lessons a day to the teachers in secondary education, workshops and out-of-school trip-review activities can be performed in their remaining hours to improve students' innovative skills. If students take half-day lessons in the morning instead of doing full-day in-school education and participate in workshops of the courses they have taken as practical courses and the clubs they are registered, and support the work of various social services or voluntary organizations, then they will get the opportunity to gain social innovation skills and experience on environmental developments in addition to theoretical knowledge.

If the project works towards developing product innovations in schools are carried out by the expert teachers who have project trainings, then this will be very effective in exploring gifted children and developing projects that can become successful in national and international project competitions. Different learning areas outside the classroom can be offered to students, by setting up "innovation workshops" that allow students to explore their skills. Depending on their ages and interests, students in the guidance of expert teachers can make computer software, robotics technological studies, social innovation projects and artistic works that they can prepare in simple level. Thus, experience environments enabling a rapid spread of innovation culture in educational institutions can be created.

The development of pedagogical innovation is also seen as a separate place in the relation between innovation and performance. According to the training report of OECD countries 2012 "Teaching Practices and Pedagogical Innovation Evidence from TALIS", teaching methods shape the learners' learning experience and increase their motivation. According to the report, when teachers collaborate in developing different teaching methods, they are able to work more actively with their students. In other words, this development is possible by applying different teaching methods to the teachers' class and by bringing them together to form professional learning communities.

According to the education report covering OECD countries, as a result of quantitative studies, it was observed that teachers who use different teaching methods and who are involved in professional learning communities have higher self-sufficiency, that they can get more feedback from their schools and make better assessment, and that they are also more active in out-of-school professional development activities. It was also stated that teaching methods are more frequently used in small-scale schools and have more diversity compared to large-scale schools.

Today, students solve a problem often using conventional methods; for example, while finding a solution using a classical equation is more common in solving a mathematical problem, they do not prefer to describe the current problem by explaining, drawing or painting. In this sense, students should be taught different problem-solving techniques in the sense of developing creative solutions that enable students to develop their ability to produce knowledge and to look at a problem from different perspectives. Therefore, the development of course materials by academicians for improving the skills of students to acquire knowledge and also design and use knowledge according to their own needs, will help to satisfy a significant training need. In addition, academicians working in the field of architecture can now make significant contributions to the development of innovation in the education sector by conducting reviews on creative space designs, which, unlike the usual school architecture, offer more learning space to students.

Innovations made in the sense of organizational career in educational institutions can also accelerate innovation works. It has been observed in the current applications that many teachers particularly working in project schools who have not received project training cannot exhibit the expected performance, but many teachers with innovative skills are not sufficiently assessed in the school they are working in. It is especially important that teachers with project training and highly innovative skills are assigned in the relevant units by ensuring the teacher-school match. It may be very useful for the innovation management that academicians who work in the field of human resources carry out studies about the appointment process of the teachers who have mastered the innovation projects. Thus, an innovative organizational 
career planning can be made in public schools, allowing for the appropriate evaluation of teacher employment.

\section{Acknowledgement}

We are thankful for support from the Turkey Ministry of National Education. We also appreciate assistance in data access from the high schools in Istanbul.

\section{References}

Amabile, Teresa. M. (1988). A Model of Creativity and Innovation in Organization. Research in Organizational Behavior, Vol.10:123-167.

Anderson, Neil, Potočnik, Kristina, Zhou, Jing (2014). Innovation and Creativity in Organizations: A Stateof-the-Science Review, Prospective Commentary, and Guiding Framework. Journal of Management. 40 (5): 1-94.

Andersen, O. and Kheam, L.S. (1998), "Resource-Based Theory and International Groeth Strategies an Exploratory Study", International Business Review, Vol.7, pp. 162-184

Avcl, U. (2009). The Impact of Learning Orientations on Innovation Performance: An Investigation in Muğla Marble Sector. ZKU Journal of Social Sciences, v.5, i.10:121-138.

Baron, R.M. and Kenny, D.A.(1986), "The Moderator-Mediator Variable Distinction in Social Psychological Research: Cenceptual, Strategic and Statistical Consideration”, Journal of Personality and Social Psychology, Vol.51 (6), pp. 1173-1182

Chen, Guoquan (2005). Management Practices and Tools for Enhancing Organizational Learning Capability. SAM, Advanced Management Journal, Winter, pp.4-35.

Celuch, K.G.,C.J. Kasouf and V. Peruvemba(2002), "The Effect of Perceived Market and Learning Orientation on Assessed Organizational Capabilities", Industrial Marketing Management, Vol.31, pp. $545-554$

Cohen, Wesley M., Levinthal, Daniel A. 1990. Absorptive Capacity: A New Perspective on Learning and Innovation. Administrative Science Quarterly. v. 35. p.1:128-152.

Dodgson, Mark. Gann, David. Salter, Ammon. 2006. The Role of Technology in the Shift Towards Open Innovation: the Case of Procter \& Gamble. R\&D Management. v. 36. p. 3: 333-346.

Dutta, Soumitra, Lanvin, Bruno, and Wunsch-Vincent, Sacha (2016). The Global Innovation Index 2016 Winning with Global Innovation. Ithaca, Fontainebleau, and Geneva: Cornell University, INSEAD, and WIPO.

Döbert ,H., Klieme E. , and Sroka, W. ,(2004) "Vertiefender Vergleich der Schulsysteme ausgewählter PISATeilnehmerstaaten (Frankfurt: Deutsches Institut für pädagogische Forschung.

Fadaee, Akbar and Abd Alzahrh, Haitham Obaid (2014). Explaining the Relationship between Creativity, Innovation and Entrepreneurship. Int. J. Econ. Manag. Soc. Sci. 3 (12): 1-4.

Garvin, David A.(1993). Building a Learning Organization. Harvard Business Review. July-August, pp. 7891.

Winthrop. Rebecca, McGivney. Eileen, Timothy, Williams. P, and Shankar. Priya (2016) Innovation and Technology to Accelerate Progress in Education. Report to the International Commission on Financing Global Education Opportunity. Washington: The Center for Universal Education at the Brookings Institution.

Kaleka A,.(2002) "Resources and Capabilities Driving Competitive Advantage in Export Markets: Guidelines for Industrial Exporters", Industrial Market Management,Vol.31, pp.273-283.

Koçoğlu, İpek. İmamoğlu, Salih Zeki. İnce, Hüseyin. 2011. The Relationship Between Organizational Learning and Firm Performance: The Mediating Roles of Innovation and TQM. Journal of Global Strategic Management. i.9: 72-88.

Lall, Sanjaya. 1992. Technological Capabilities and Industrialization. World Development. Volume 20, Issue. 2: 165-186, February. 
Esendemir \& Zehir / International Journal of Research in Business and Social Science,

Vol 6 No 4, 2017 ISSN: 2147-4486

Luecke, Richard. 2008. İş Dünyasında Yenilik ve Yaratıcııı. Çev.: Turan Parlak. İstanbul: İş Bankası Kültür Yayınları.

Meeus, Marius T. H. Oerlomans, Leon A. G. Hage, Jerald. 2001. Sectoral Patterns of Interactive Learning: An Empirical Exploration of a Case in a Dutch Region. Technology Analysis \& Strategic Management. v. 13. i. 3:407-431.

Nelson, Richard R., Phelps, Edmund S. 1996.Investment in Humans, Technological Diffusion, and Economic Growth. The American Economic Review. v. 56, i. 1-2: 69-75.

Ozan, M. B., and Karabatak, S. (2013). Secondary school administrators' approaches to innovation management and problems they encounter. International Online Journal of Educational Sciences, July $\backslash$ August Volume: $37-51$.

Therin, François. 2002. Organizational Learning and Innovation in High-Tech Small Firms. Proceedings of the 36th Hawaii International Conference on System Sciences. January 6-9. Hawaii:IEEE Computer Society.

Uzkurt, Cevahir. 2010. İnovasyon Yönetimi: İnovasyon Nedir, Nasıl Yapılır ve Nasıl Pazarlanır? (Innovation Management: What is Innovation, How is it Constructed and How is it Marketed?) File. Ankara Sanayi Odası Yayın Organı. Temmuz/Ağustos 210: 37-51.

Vieluf, Svenja, Kaplan, David, Klieme, Eckhard and Bayer, Sonja (2012). Teaching Practices and Pedagogical Innovation: Evidence from TALIS. Paris: OECD Publishing.

Winthrop, Rebecca, McGivney, Eileen, Williams, Timothy P. and Shankar, Priya (2016).

Yamac, K. (2001). What is this Innovation? Journal of Science, Education and Thought, 1(3): 6.

Yamaç, Kadri. 2001. Nedir Bu İnovasyon? Üniversite ve Toplum. v. 1, i. 3: 6.

Vakola, Maria and Yacine Rezgui; (2000), "Organisatinal Learning and Innovation in the Construction Industry", The Learning Organization, 7(4), pp. 174-183. 